\title{
Crowding in Public Transport: A Review of Objective and Subjective Measures
}

\author{
Zheng Li and David A. Hensher \\ The University of Sydney
}

\begin{abstract}
Crowding in public transport is becoming a growing concern as demand grows at a rate that is outstripping available capacity. To capture the user benefits associated with reduced crowding from improved public transport, it is necessary to identify the relevant dimensions of crowding that are meaningful measures of what crowding means to travelers. There are a number of objective and subjective measures of crowding promoted in the literature, with some objective measures being used as the basis of a standard of acceptable levels of practice. There is a disconnection between objective measures and subjective measures, the latter representing what matters to users. We illustrate the difference in a comparison of monitored crowding levels using crowding measures defined by the rail operator/authority in Sydney and Melbourne, Australia, and the level of crowding experienced by rail passengers from two recent surveys to reveal the significant gap between objective and subjective measures of crowding.
\end{abstract}

\section{Introduction}

Two influences on public transport modal choice that are growing in relevance are trip time reliability and crowding. These sources of additional user benefits should be included with the traditional travel time and out-of-pocket cost attributes to represent the wider set of user benefits from investment in public transport. In 
a benefit-cost framework, justifying investment in public transport is becoming increasingly challenging, and any additional sources of user benefit that can assist in improving the prospect of such investments should be included. Li and Hensher (2011) reviewed the literature on willingness to pay for reduced crowding and concluded that the benefits from reduced crowding (variously defined) are significant and often as great as travel time savings. However, to be able to apply the available willingness to pay estimates, it is necessary to collect data on the experienced levels of crowding (in contrast to applying some objective standard), since this provides the reference point for opportunities to improve crowding as a significant source of user benefit.

Currently, however, there is a dearth of data collected on crowding levels that aligns with what matters to users in terms of their behavioral response and, hence, user benefit streams; what is typically collected are data on crowding against a standard such as the number of standing passengers per square meter, which, although informative, is not necessarily an appropriate representation of user subjective preference (and, hence, willingness to pay) for improved levels of crowding. This paper reviews the evidence, limited as it is, on objective measures of crowding that typically are used to establish standards of practice, as well as the evidence on subjective measures of crowding, as the basis of highlighting the gap between the two dimensions of crowding - the standard (i.e., objective) and the perceived (i.e., subjective) metrics. We are not in a position to definitely map the two dimensions, which is a crucial requirement for translating objective improvements into equivalent subjective gains that then can be applied, via willingness to pay estimates, to obtain the additional user benefits of public transport investment. This paper focuses on promoting the case for research to ensure the mapping, providing one possible way forward using an example from recent research by Tirachini et al. (2012).

What exactly is the meaning attributed to crowding? Evans and Lepore $(2007,90)$ suggested that crowding occurs "when the regulation of social interaction is unsuccessful and our desires for social interaction are exceeded by the actual amount of social interaction experienced." In the specific context of railways, Mohd Mahudin et al. (forthcoming) reviewed a number of studies on crowding and concluded that crowding has a negative impact on passengers in terms of psychological or emotional distress. A survey conducted in London showed that public transport passengers were willing to stand for up to 20 minutes if the service is fast and reliable; however, crowding outweighed these benefits (The Transport Commit- 
tee 2003). According to a recent Australian survey, the time limit for standing in a crowded rail carriage is approximately 15 minutes on average (Thompson et al. 2012). Thompson et al. also found that crowding is the problem most frequently encountered by Australian train passengers. Crowding is also a major issue in other countries such as the UK (see Cox et al. 2006).

From a passenger's perspective, experienced crowding leads to increased dissatisfaction (e.g., stress and less privacy) during traveling. From an operator's perspective, the service frequency or vehicle size is significantly influenced by the level of ridership, which sends a signal to respond if the monitored crowding level exceeds the benchmark standard. Crowding is regarded as a key service attribute for public transport, along with other factors such as travel time and reliability (see, for example, the service quality index developed by Hensher et al. 2003). Given the increasing importance of crowding on both the disutility to existing public transport users and the influence it has on whether to use public transport or not, it is timely to review the current measures of crowding defined by transport authorities/operators, and to evaluate whether they appropriately reflect traveler experiences and perceptions of crowding. We have not found a single study that examines whether monitored crowding by an authority can reflect public transport user experiences and is an appropriate metric for obtaining crowding reduction benefits, given willingness to pay estimates. A better understanding of crowding would, in turn, help design more appealing public transport systems to attract more users. This is especially important to the modal shift from car travel to public transport, given that a reason that cars are used for commuting instead of public transport is a loss of privacy in public transport due to crowding (Joireman et al. 1998; Ibrahim 2003; Evans and Lepore 2007). The paper complements Li and Hensher (2011), which reviewed the literature on the willingness to pay to reduce crowding.

\section{Measures of Crowding: Conventional Bus and Bus Rapid Transit (BRT)}

The number of standing passengers per square meter $\left(\mathrm{m}^{2}\right)$ is an objective standard measure for crowding used by many conventional bus services around the world. However, the benchmarks that define the unacceptable crowding levels vary across different countries or regions. For example, four standees per $\mathrm{m}^{2}$ is the benchmark for Europe (UITP 2009) and for Australia (Diec et al. 2010). This number increases to five standees per $\mathrm{m}^{2}$ for the USA' (TRB 2006) and reaches eight per $\mathrm{m}^{2}$ for China's bus sector (AQSIQ 2004). Just like the crowding measure used in the conventional 
bus industries, ITDP (2012) also used standing passengers per square meter to measure the level of crowdedness for bus rapid transit (BRT) systems, where overcrowding on BRT buses is defined as more than five standing passengers per square meter ( 0.46 per square foot) during the peak hour.

Despite the standards, many systems are experiencing overcrowding that is noncompliant with the standard. Overcrowding has become a major issue for conventional and BRT systems, especially in the developing world. For example, there was a major protest against overcrowded services provided by Bogotás BRT system (Transmilenio) on March 9, 2012. This system became far too overloaded, given that its actual patronage grew to double its design capacity. ${ }^{2}$ In another example, Curitiba's BRT system also became overcrowded (see Duarte and Ultramari 2012). The influence of overcrowding on BRT performance is highlighted in ITDP (2012): "Many [BRT] systems which are generally well-designed are being operated such that buses are so overcrowded that the systems become alienating to passengers" (45).

\section{Measures of Crowding: Passenger Train}

Compared to bus, much more diverse crowding measures are defined in the passenger rail industry. For passenger rail, different specifications for measuring crowding are found across countries and even within a country, which are summarized below.

\section{Rail Crowding Measures in the UK}

The passengers in excess of capacity (PiXC) is a crowding measure that applies to all London and South East operators' weekday train services arriving at a London terminus during the morning peak from 07:00 to 09:59, and those departing during the afternoon peak from 16:00 to 18:59 (Office of Rail Regulation 2011). The overall PiXC figure, derived by combining the PiXC of both peaks, considers the planned standard class capacity ${ }^{3}$ of each train service, as well as the actual number of standard class passengers on the service at the critical point (i.e., the location on a train's journey with highest passenger load). PiXC is the number of standard class passengers that surpass the planned capacity for the service. The PiXC is given in percentages, calculated as the difference between the number of actual passengers and the capacity of the train divided by the actual passenger number. It is zero if the number of passengers is within the capacity.

The UK Department for Transport (DfT) monitors the crowding levels annually. Under the historic PiXC regime, the current benchmarks to define the acceptable PiXC levels are 4.5 percent on either the morning or afternoon peak and 3.0 per- 
cent for both peaks (Office of Rail Regulation 2011). The Office of Rail Regulation (2011) reports the calculated PiXC figures on a typical weekday from 2008 to 2010. Out of 60 observations for morning or afternoon peak, 11 observations exceed the defined acceptable PiXC level (4.5\%). Out of 30 observations for the overall performance, eight PiXCs surpassed the benchmark of 3.0 percent.

The PiXC can be converted into a common measure for crowding, i.e., the number of standing passengers per square meter (standing passengers per $\mathrm{m}^{2}$ ). For example, a PiXC of 40 percent is equivalent to five standing passengers per $\mathrm{m}^{2}$ (London Assembly Transport Committee 2009). The standing passenger density is used by many rail industries around the world (Hirsch and Thompson 2011). Figure 1 provides the crowding levels based on standing passenger density, prepared by Transport for London for a morning peak in 2009, where Transport for London define a service as crowded if it has 2-3 passengers per $\mathrm{m}^{2}$. This figure illustrates a spatial pattern, i.e., in London, train services in suburbs tend to be less crowded than services in inner-city areas. According to Office of Rail Regulation (2011), the benchmark for train crowding is 2.22 passengers per $\mathrm{m}^{2}$ for most train operators in the UK.

Another crowding measure used in the UK is the percentage of standard class passengers standing, which is similar to PiXC, with the difference being the use of the planned number of standard class seats as the capacity for a rail service which has no allowance for standing. The Office of Rail Regulation (2011) reported the percentage of standard class passengers standing on a typical weekday in autumn 2010 varied from 1.0 percent (afternoon peak departure at Nottingham) to 14.0 percent (morning peak arrival at Leeds).

The difference between the PiXC ${ }^{4}$ and the percentage of standard class passengers standing is that the calculation of the former allows standing for journeys of up to 20 minutes as an additional component of capacity; the latter makes no allowance for standing where the capacity includes only the number of seats. The PiXC is mainly used to measure the crowding levels of commuter train services (e.g., within London), while for regional services with long journey times, the percentage of standard class passengers standing is used in the UK. It seems acceptable to have standing passengers (and, hence, standing allowance) for shorter journeys (e.g., commuting). This difference also has an impact on the design of rolling stock-for example, fewer seats and a higher standing capacity for services with shorter journey times so as to carrier more passengers (Office of Rail Regulation 2011). There- 


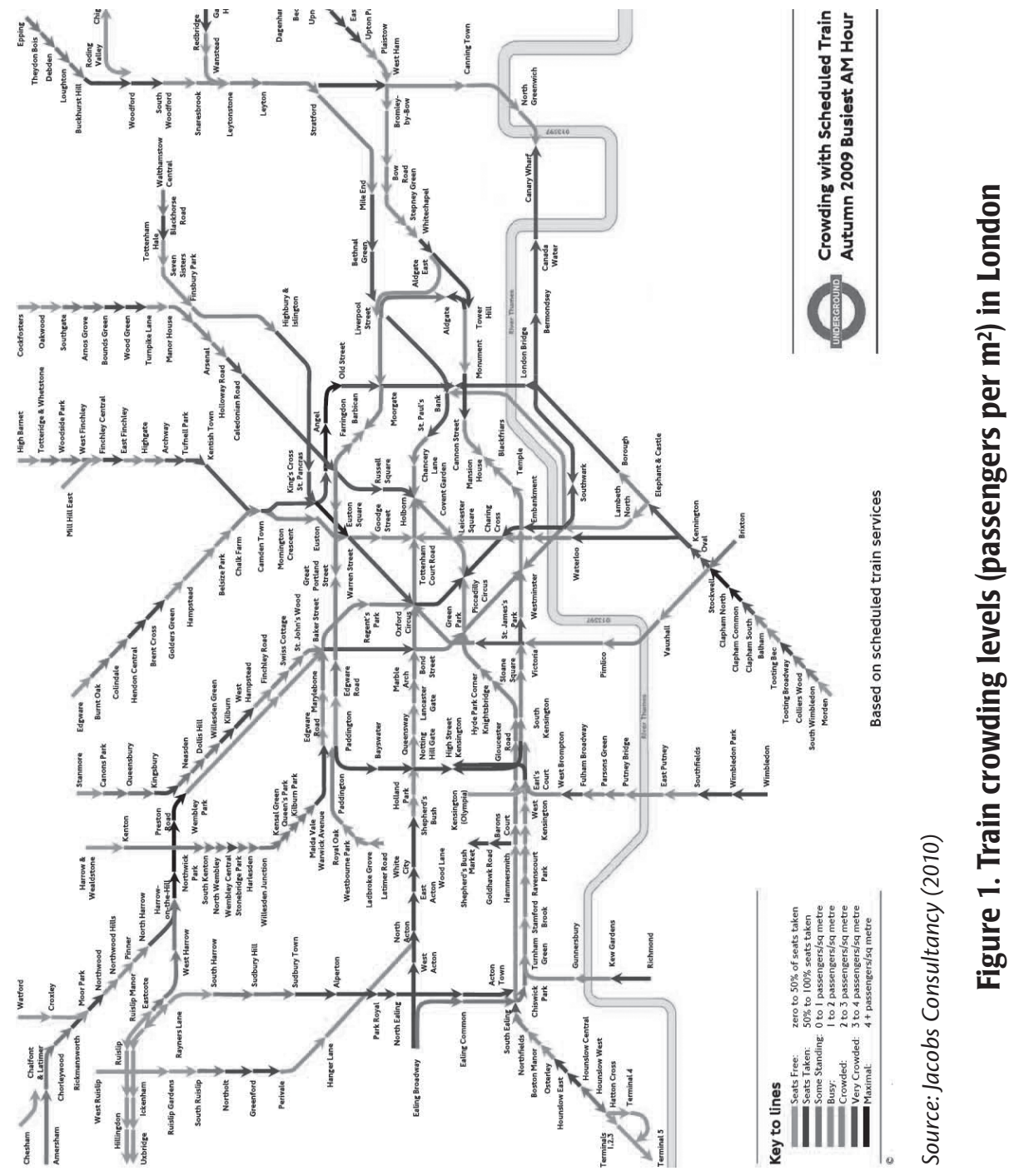


fore, these two measures (with and without standing allowance) service different trip purposes.

\section{Rail Crowding Measures in the USA}

A key measure used by many U.S. transit authorities to evaluate in-vehicle crowding is load factor (passengers per seat), which is calculated as the number of passengers divided by the number of seats. A load factor of 1.0 indicates that all seats are occupied. With regard to load factor, different benchmarks are defined according to the nature of the service-for example, 1.0 for long-distance commute trips and high-speed mixed-traffic operations, 2.0 for inner-city rail service, and in between for other services, according to the current Transit Capacity and Quality of Service Manual (TCQSM)5 (TRB 2003).

The TCQSM (TRB 2003) defined the thresholds for the level of service (LOS) with respect to in-transit crowding, shown in Table 1. At LOS levels A, B, and C ( $>0.51$ $\mathrm{m}^{2}$ per standing passenger), all passengers can sit, while some passengers need to stand at LOS load level D. LOS E is the defined crowding threshold, i.e., $0.20-0.35$ $\mathrm{m}^{2}$ per standing passenger, which is equivalent to $2.86-5$ standing passengers per $\mathrm{m}^{2}$. LOS $\mathrm{F}\left(>5\right.$ standing passengers per $\mathrm{m}^{2}$ ) represents crush loading levels.

\section{Table 1. LOS Thresholds for Crowding}

\begin{tabular}{|c|c|c|c|l|}
\hline \multirow{2}{*}{ LOS } & Load Factor & \multicolumn{2}{|c|}{ Standing Passenger Area } & \multirow{2}{*}{ Comments } \\
\cline { 2 - 4 } & (passengers/seat) & $\left(\mathbf{f t}^{2} /\right.$ passenger $)$ & $\left(\mathbf{m}^{2} /\right.$ passenger $)$ & \multicolumn{1}{|l}{} \\
\hline A & $0.0-0.50$ & $>10.8^{\wedge}$ & $>1.0^{\wedge}$ & $\begin{array}{l}\text { No passenger need sit next } \\
\text { to another }\end{array}$ \\
\hline B & $0.51-0.75$ & $8.2-10.8^{\wedge}$ & $0.76-1.0^{\wedge}$ & $\begin{array}{l}\text { Passengers can choose } \\
\text { where to sit }\end{array}$ \\
\hline C & $0.76-1.0$ & $5.5-8.1^{\wedge}$ & $0.51-0.75^{\wedge}$ & All passengers can sit \\
\hline D & $1.01-1.25^{*}$ & $3.9-5.4$ & $0.36-0.50$ & $\begin{array}{l}\text { Comfortable standee load } \\
\text { for design }\end{array}$ \\
\hline E & $1.26-1.50^{*}$ & $2.2-3.8$ & $0.20-0.35$ & Maximum schedule load \\
\hline F & $>1.50^{*}$ & $<2.2$ & $<0.20$ & Crush load \\
\hline
\end{tabular}

*Approximate value for comparison, for vehicles designed to have most passengers seated. LOS is based on area.

$\wedge$ Used for vehicles designed to have most passengers standing.

In addition to load factor, another crowding measure used in the U.S. is standing passenger area (space $\left[\mathrm{m}^{2}\right]$ per standing passenger), which can be easily converted into the number of standing passengers per square meter (standing passengers per 
$\mathrm{m}^{2}$ ) (see Table 1). As an example, for the crowding level of maximum schedule load (which is the defined crowding threshold), the load factor range is 1.26-1.50, while the corresponding measure of standing passenger area is $0.20-0.35$ square meter per standing passenger (or 2.86-5 standing passengers per $\mathrm{m}^{2}$ ).

\section{Rail Crowding Measures in Australia}

There are five major metropolitan rail systems in Australia: CityRail, Metro Trains, Transperth, Adelaide Metro, and Queensland Rail, located in Sydney, Melbourne, Perth, Adelaide and Brisbane, respectively, and each has its own measure of crowding. Therefore, the measures for rail crowding in Australia are not consistent. For example, Sydney's CityRail, operated by RailCorp, uses the number of standing passengers per square meter to measure crowding, and its benchmark is 1.9 standees per $\mathrm{m}^{2}$ (The Audit Office of New South Wales 2011). An alternative crowding measure for CityRail is load factor (passengers per seat), and the corresponding target set by the Minister in the Rail Services Contract ${ }^{6}$ is no more than 5 percent higher than 135 percent of seat capacity during the peak hours (The Audit Office of New South Wales 2011). Melbourne uses the rolling hour average loads to measure crowding in its Metro trains, and if the number of average passengers per train during a given hour, as counted at the Melbourne city cordon, exceeds 798, a railway line is considered overcrowded (Department of Infrastructure 2008). For Queensland Rail, the target of the length of standing time is no more than 20 minutes (Queensland Rail 2011).

\section{Monitored Crowding vs. Experienced Crowding: Evidence from Melbourne and Sydney}

Melbourne Metropolitan Train Load Standard Surveys are conducted twice a year to measure passenger loads, which are used to determine when and where extra services are needed to reduce crowding. The Metropolitan Train Load Standard survey ${ }^{7}$ by the Department of Transport (2011) shows that in 2011, the number of trains exceeding the crowding benchmark (when rolling hour average loads $>798$ ) were lower than the previous four years, ${ }^{8}$ for both morning peak (city-bound) and afternoon peak services (outbound), as shown in Figures 2 and 3. 


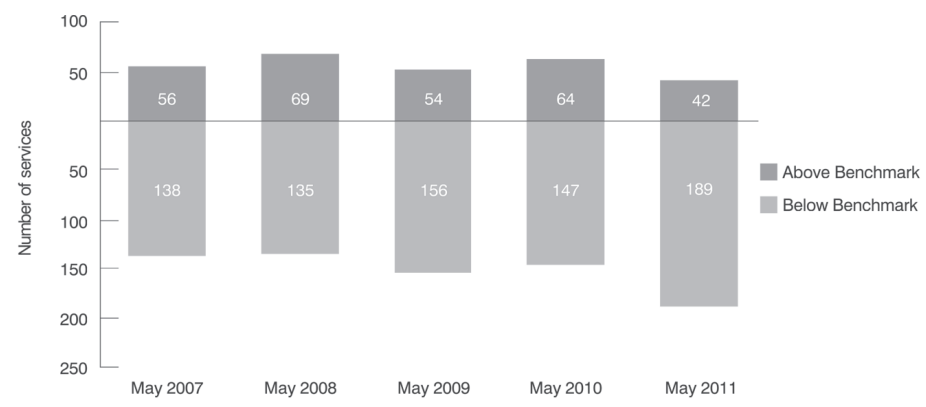

Number of AM Peak services exceeding the benchmark

\begin{tabular}{lrrrrrr}
\hline & May 2007 & May 2008 & May 2009 & May 2010 & May 2011 \\
\hline Number of services & 56 & 69 & 54 & 64 & 42 \\
\hline Percentage of peak services & 28.9 & 33.8 & 25.7 & 30.3 & 18.2 \\
\hline $\begin{array}{l}\text { Percentage of passengers on } \\
\text { services exceeding the benchmark }\end{array}$ & 41.3 & 46.5 & 35.8 & 41.4 & 25.8 \\
\hline
\end{tabular}

Source: Department of Transport (2011)

\section{Figure 2. Passenger loading levels for the morning peak,} May 2007 to May 2011

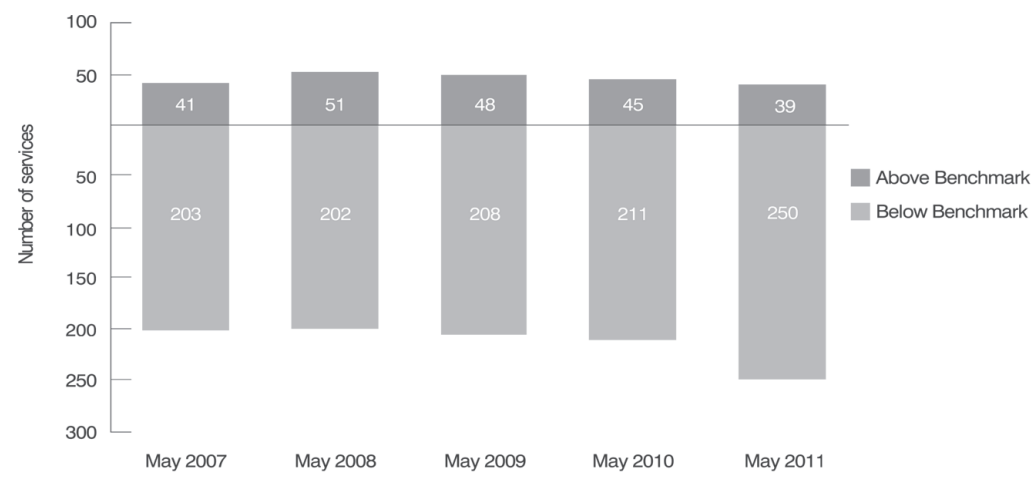

Number of PM Peak services exceeding the benchmark

\begin{tabular}{lrrrrrr}
\hline & May 2007 & May 2008 & May 2009 & May 2010 & May 2011 \\
\hline Number of services & 41 & 51 & 48 & 45 & 39 \\
\hline Percentage of peak services & 16.8 & 20.2 & 18.8 & 17.6 & 13.5 \\
\hline $\begin{array}{l}\text { Percentage of passengers on } \\
\text { services exceeding the benchmark }\end{array}$ & 27.8 & 32.2 & 29.8 & 27.8 & 23.0 \\
\hline
\end{tabular}

Source: Department of Transport (2011)

\section{Figure 3. Passenger loading levels for the afternoon peak, May 2007 to May 2011}


Figure 2 shows that only 18.2 percent of AM peak services (or $25.8 \%$ passengers on services) exceeded the defined benchmark, and the corresponding statistics for PM peak services are 13.5 percent of services or 23.0 percent passengers according to Figure 3 . The results would suggest that there were no serious crowding problems on Melbourne train services in 2011. However, this is the opposite of findings from a survey conducted by Canstar Blue in 2011 (http://www.canstarblue.com.au/ travel/city-trains/). This survey sampled 2,500 train commuters and asked them to provide feedback on a range of categories of rail services (e.g., fare, reliability, safety). This independent survey shows that Melbourne commuters are least satisfied with their train services, and 55 percent of surveyed Melburnians believed that "overcrowding was substantially impacting their quality of life," which is higher than people living in other cities (e.g., 27\% for Adelaide). Victorian Greens MPs have regularly collected travelers' real experiences of crowding on Melbourne trains and published results on their website ( $h t t p: / / m p s . v i c . g r e e n s . o r g . a u / w e w o n t s t a n d f o r i t)$. The collected data show that trains were overcrowded even during off-peak hours, and many passengers were being left behind at stations due to overcrowding. ${ }^{9}$

In Sydney, load factor is the crowding measure defined in the Rail Services Contract. RailCorp also has its internal crowding measure (i.e., the number of standing passengers per square meter). RailCorp have been monitoring the crowding levels based on the two measures. Figure 4 shows the monitored rail crowding from 2007 to 2011 in terms of standees per $\mathrm{m}^{2}$. Figure 5 provides the load factors from 2005 to 2011.

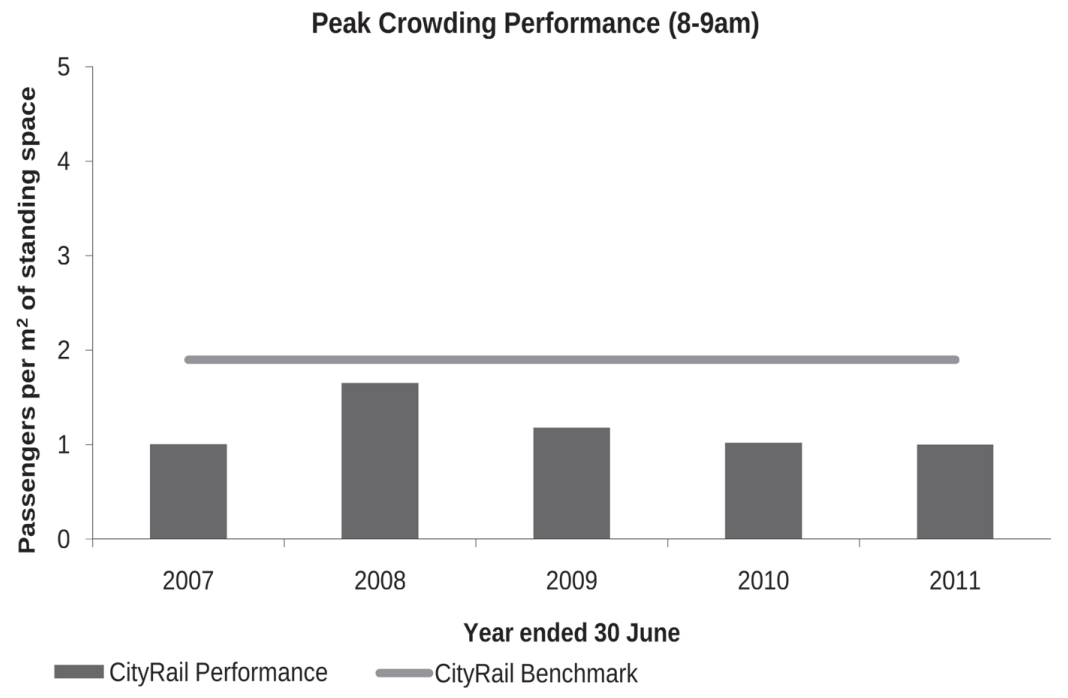

Figure 4. RailCorp's internal crowding measure (standees per $\mathbf{m}^{2}$ ) 


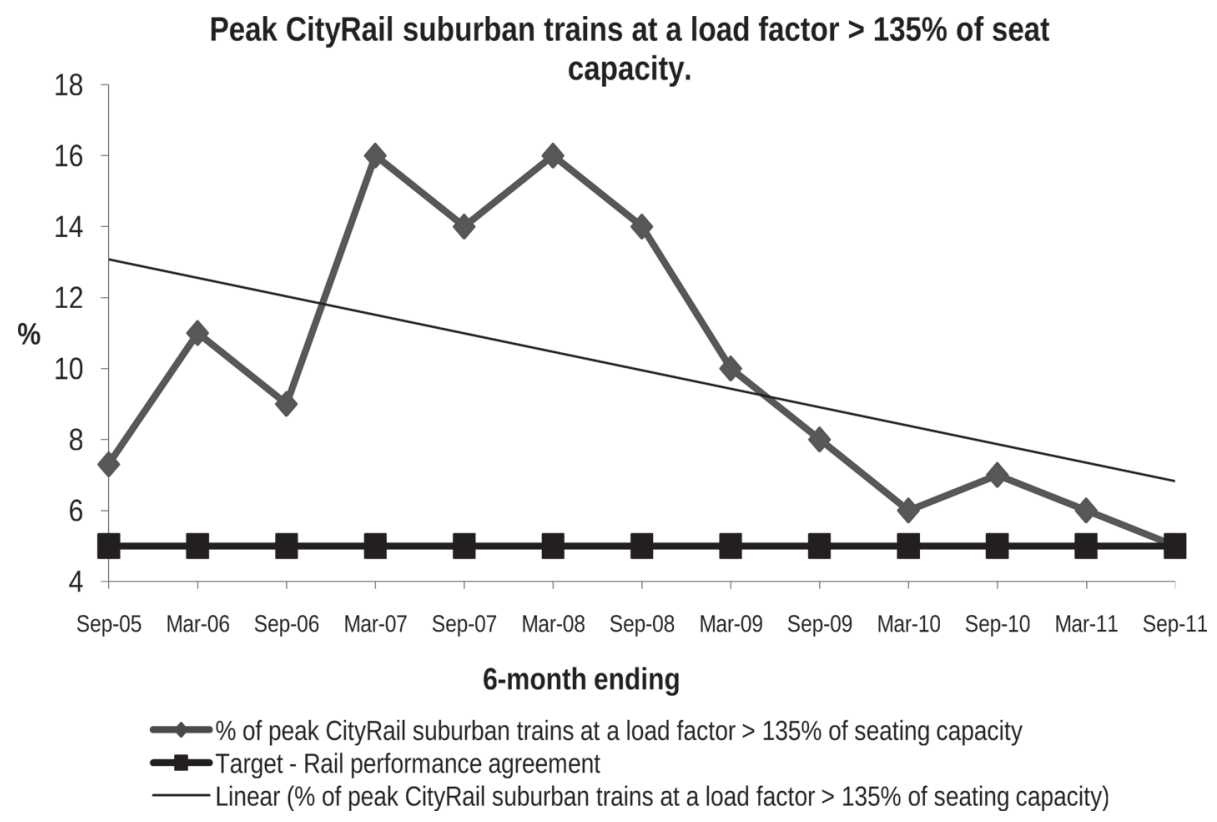

\section{Figure 5. CityRail crowding measure defined by Rail Services Contract (load factor $>135 \%$ )}

The monitored crowding levels between 2007 and 2011 in terms of standees per $\mathrm{m}^{2}$ (RailCorp's internal crowding measure) are given in Figure 4, which illustrates that during the survey periods (March each year), the monitored crowding levels were well below the crowding benchmark of RailCorp ( 1.9 standees per $\mathrm{m}^{2}$ ) between 8 and $9 \mathrm{AM}$, where the highest monitored crowding occurred in 2008 close to the benchmark. This suggests no crowding issues on CityRail.

However, Figure 5 tells a different story, where the horizontal axis is the time period when the survey was conducted (conducted every six months, with the most recent in September 2011), and the vertical axis is the level of crowding higher than 135 percent of seat capacity (for example, $6 \%$ means that the crowding level is the number of passengers carried is $6 \%$ higher than $135 \%$ of seat capacity). In Figure 5 , the dashed line is the target set by the Rail Services Contract (i.e., no more than $5 \%$ higher than $135 \%$ of seat capacity); and all observed crowding levels are above this target, suggesting the presence of crowding, despite the fact that there is a decreasing trend (linear line which is best fitting regression of load factors over time) in load factors, where the lowest level of crowding was 7 percent higher than 135 percent of seat capacity, as monitored in September 2011. 
According to RailCorp's own crowding benchmark, overcrowding is not an issue for Sydney's CityRail, given that the observed density was well below its benchmark. However, the Canstar Blue survey revealed that overcrowding on Sydney train services is similar to the situation in Melbourne. On February 12, 2012, 7News reported that complaints about Sydney train services (particular on overcrowding) reached a record high. ${ }^{10}$

The comparison shows that there is a huge gap between the monitored crowding by the rail authority/operator and the experienced crowding by rail passengers in Melbourne and Sydney, and we suspect that the same evidence would apply if it were collected on all systems discussed above. A potential contributor to this gap is that the monitored result is too aggregate, which is reported as an average number over a period of time (e.g., one hour) and across several stations (e.g., North Melbourne, Jolimont, and Richmond for Melbourne). ${ }^{11}$ Moreover, the density-based measure fails to accommodate other important factors such as the length of journey in a crowded environment and whether standing or seated. The experience of crowding is more complicated than a density measure. For example, evidence from the psychology literature suggests that personal space invasion rather than overall density is the key factor to perceived crowding (see, e.g., Sundstrom et al. 1975; Worchel and Teddlie 1976). In the context of transport, Evans and Wener (2007) investigated personal space invasion and crowding, where 139 New York City train commuters were sampled. They found that seat density (the number of people sitting in the same immediate row the passenger was seated in to the number of total seats in the row) is related to stress rather than overall load factor (the ratio of the number of passengers to the number of seats) and, hence, claimed that the close presence of other passengers in a train carriage is more important to the experience of crowding than the overall train passenger density. ${ }^{12}$ Most important, passenger perceptions of crowding may be subjective, which cannot be accommodated by the objective measure of density.

\section{Subjective or Psychological Components of Crowding}

The above review shows that density (the ratio of passengers to space) is commonly used as the measure of crowding by many transport authorities. Mohd Mahudin et al. (2012) conducted a comprehensive literature review on existing studies of rail crowding and concluded that crowding is also defined and accessed based on measurements of passenger density and train capacity in the literature. Li and Hensher (2011) reviewed public transport crowding valuation research, with a focus on ways of representing crowding in stated preference (SP) experiments such as seat occu- 
pancy rate, load factor, and the number of standing passengers per square meter, which is in line with Mohd Mahudin et al.'s conclusion.

However, in the broader literature, it has long been recognized that density cannot fully capture the experience of individuals in a given space (Day and Day 1973; Evans 1979). A number of studies also claimed that the major limitation of using density as a crowding measure is a lack of consideration of individual perceptions of in-vehicle crowdedness (see, e.g., Turner et al. 2004; Cox et al. 2006). In the context of passenger rail, Cox et al. (2006) concluded that the perception of crowding is created "from an interplay of cognitive, social and environmental factors, whereas density refers to objective physical characteristics of the situation" (248). Evans and Lepore (2007) claimed that although perceived crowding is related to passenger density, they are not identical. Passenger perceptions are subjective, which are influenced by many factors, such as their personal characteristics and previous experience. Turner et al. (2004) highlighted that there are two dimensions of crowding: (1) objective-density and the available space, and (2) subjectiveperceived crowding.

Sundstrom (1978) proposed four categories of possible factors that may have an impact on the perception of crowding: physical antecedents (e.g., room size, noise, heat, partitions, complexity, light), interpersonal (e.g., distance, social density, interference, proximity), individual (gender preferences, experience of crowds, personality) and modifiers (e.g., duration, activity, desire for contact). Van Der Reis (1983) added some other factors such as density, expectations, experience of crowding, fear, and nature of crowd. Culture also plays a role in the perception or tolerance of crowding. Evans et al. (2000) found that residential crowding has a negative effect in terms of psychological distress across different cultures; Mexican Americans and Vietnamese Americans perceive their homes as less crowded (based on a given number of people per room) relative to African Americans or Anglo American individuals. In the transport literature, Hirsch et al. (2011) found that Australian rail passengers who are between 18 and 24 years of age, not mobility-impaired, frequent users, and willing to stand, tend to be more tolerant of crowding. Cox et al. (2006) developed a theoretical model with the relationship between density, perceived crowding and impact on health (see Figure 6). Cox et al. listed two moderating factors that might influence the impact of high density on perceptions of crowding, namely perceptions of control and predictability of events. They also claimed that crowding is a possible threat to the health of the rail industry and passengers. 


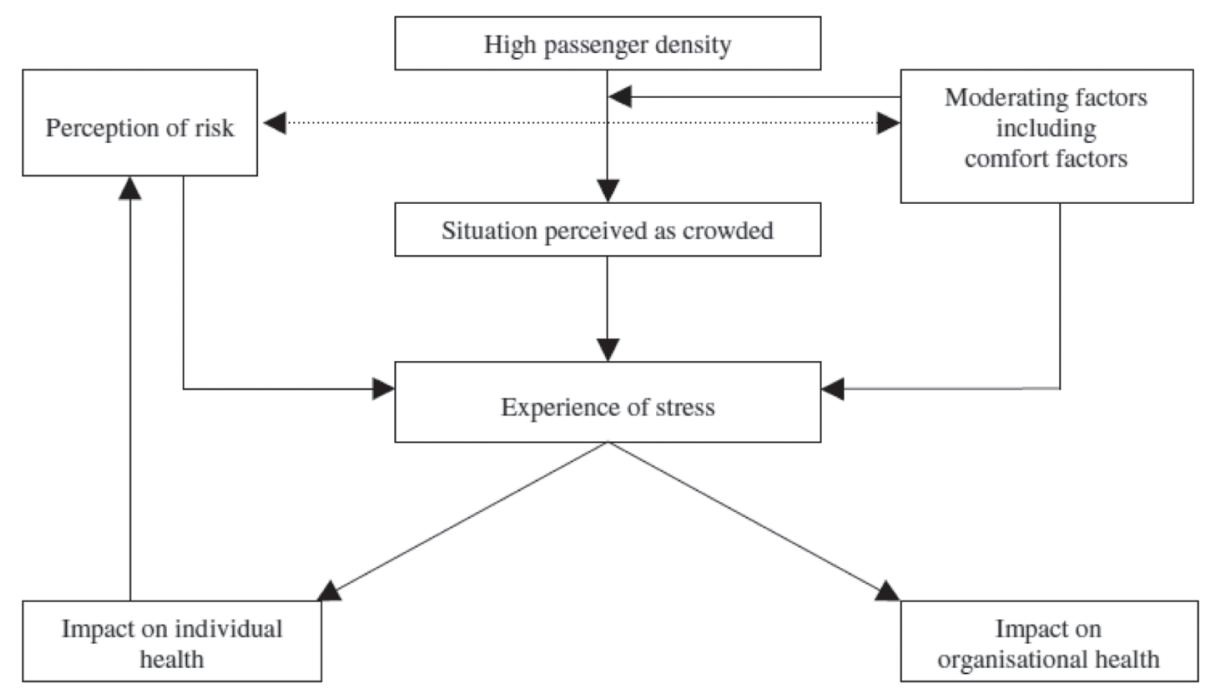

Source: Cox et al. 2006

\section{Figure 6. Model of density, perceived crowding, stress, and health}

In Australia, Hirsch and Thompson (2011) identified eight factors that may influence the perception of rail crowding: (1) expectations based on previous travel experiences; (2) environment, which includes weather (for example, perceived crowding would be overweighted in rainy conditions), and carriage, such as the quality of the air conditioning system, air flow within the carriage, the presence and design of handholds for standing passengers, the seating layout and arrangement, the cleanliness of the carriage; (3) communication-poor quality of information provided to passengers would lead to increased feelings of crowding, along with frustration; (4) control/ options/ choice-the more perceived control a passenger has to make choices, the more positive view on his/her rail experience; (5) delays, identified as a primary factor influencing perceived crowding and would exaggerate the feeling of crowding; (6) risk (safety and public health), which is strongly related to the perceived cleanliness of the carriage environment, especially the holds and the seat coverings; (7) emotion-the perception and tolerance of crowding is influenced by a passenger's emotions prior to embarkation; and (8) behavior of fellow passengers (e.g., loud phone conversations, the odor of unclean passengers, noisy school children, and a general lack of etiquette), which would also exaggerate crowding. ${ }^{13}$ 
Thompson et al. (2012) conducted a study to understand rail passenger perceptions of crowding across the five metropolitan railways in Australia, where the data were collected between 2009 and 2010. A number of potential factors were investigated, following Hirsch and Thompson (2011). Thompson et al. found reduced availability of fresh air, undesirable odors, and compromised personal space as the three most significant factors that would exacerbate passenger feelings of crowding, while participants indicated that the presence of secure poles and fixed handholds is one of the most mitigating factors to improve their tolerance of crowding. Crowding is a key issue to overall satisfaction with the service, and Thompson et al. found that a 10 percent increase in satisfaction with crowding alone would lead to a 4.6 percent increase in satisfaction with the overall train service experience.

With regard to the subjective dimension of crowding, two measures are used to capture it in the literature: (i) how crowded people feel, and (ii) how crowded people rate sitting. For example, Kalb and Keating (1981) conducted a study in a dense setting (a bookstore) and asked 201 students to answer questionnaires consisting of a series of items with a 10-point bipolar semantic differential response scale that measured perceived crowding. Factor analysis suggested that two crowding measures are conceptually different, where the feel crowd item (i.e., how crowded people feel) is associated with perceived density, constraint, distraction, and stress, while the environmental rating item (i.e., how crowded people rate seating) is loaded only with perceived density. The former is more sensitive to changes in physical density than the latter.

Mohd Mahudin et al. (2012) developed an instrument that is capable of capturing the subjective components of crowding in the context of the rail passenger. This survey instrument has three different scales, namely (1) evaluation of the psychosocial aspects of the crowded situation-"How crowded is the train that you are on today?"; (2) affective reactions to the crowded situation-"How do you feel inside the train that you commute on today"?; and (3) evaluation of the ambient environment of the crowded situation- "The physical environment inside the train that you commute on today," where each has a five-point construct-specific response scale format. The survey was conducted in Kuala Lumpur, where 525 frequent rail commuters were asked to respond on the five-point scale (see Appendix A for the full details). The passenger density variable was used as an objective measure of crowding, where respondents were presented with a scale made up of four pictorial representations (see Figure 7) ${ }^{14}$ with increasing passenger density developed by the UK Rail Safety and Standards Board (2004), and asked to rate the overall density. 
Meanwhile, the stress subscale of the Stress and Arousal Checklist (SACL) (Gotts and Cox 1988) and the worn-out subscale of the General Well-Being Questionnaire (GWBQ) (Cox and Gotts 1987) were used as the outcome measures of crowding, where a high score indicate a higher level of psychological stress and a greater feeling of exhaustion.
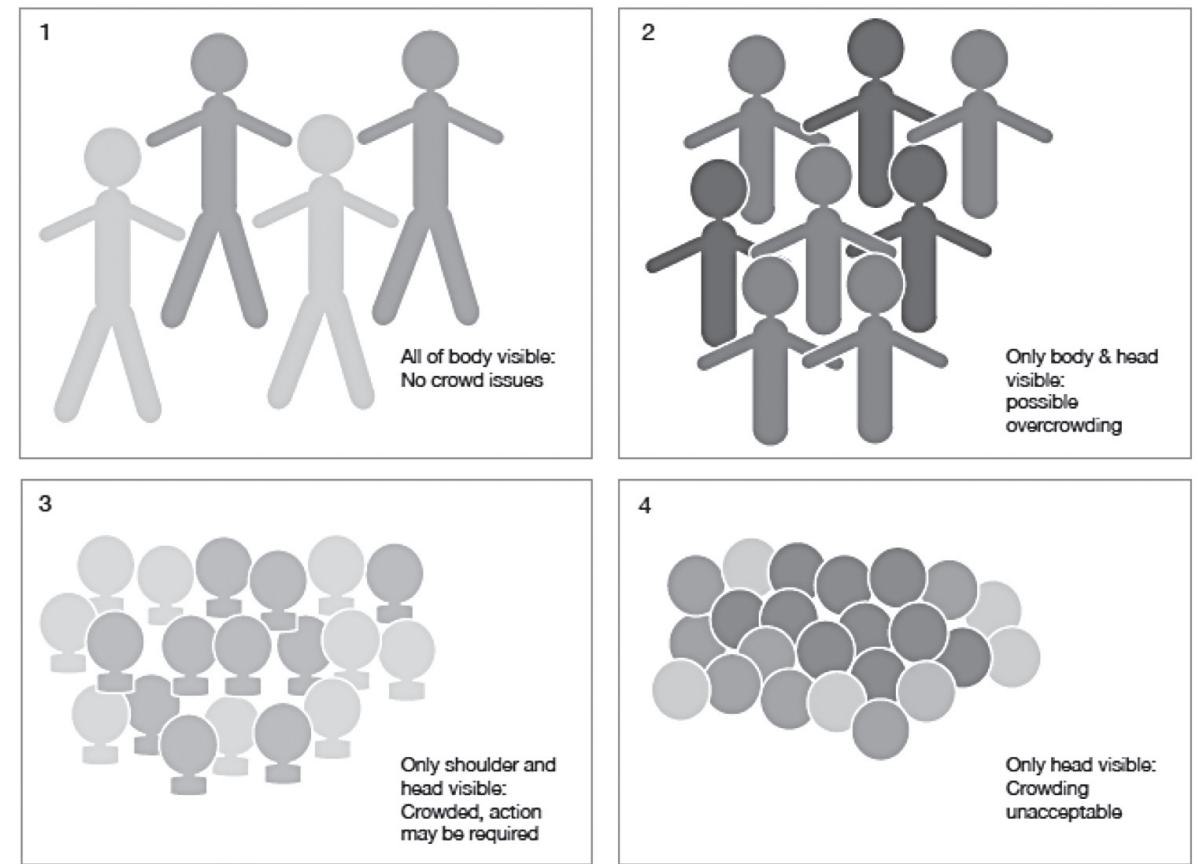

Source: UK Rail Safety and Standards Board (2004)

Figure 7. Pictorial representations of crowding

Based on the evidence, Mohd Mahudin et al. (2012) concluded that:

(1) commuters' evaluations of the psychosocial aspects of the crowded situation and of its ambient environment, alongside their rating of passenger density, significantly predict affective reactions to the crowded situation; (2) these affective reactions, in turn, significantly predict stress and feelings of exhaustion; and (3) evaluations of the psychosocial aspects of the crowded situation and of its ambient environment as well as passenger density do not directly predict stress and feelings of exhaustion (38). 
They also suggested that the relationship between rail passenger crowding and the negative outcomes is mediated by affective feelings of crowdedness.

The above review has two major implications for public transport authorities. First, crowding is two-dimensional: objective (e.g., passenger density) and subjective (perceived). The latter reflects individual travelers' assessment based on the objective crowding, as well as their previous experiences with crowding, tolerance of crowding, and personal opinions. Although it is much more difficult to continually measure perceived crowdedness, given that a traveler's perception on crowding is in her or his mind, which may directly influence choice behavior and, hence, ridership, it is important to gain information on perceived crowding, if for no other reason to understand the extent to which the (objective) standards are in line with what users perceive as acceptable levels of crowding. Opinion questions on crowding can add value in gaining insights into the acceptability of experienced levels of crowding, based on a series of questions such as: How would you describe the level of crowding on your local train services in the morning peak? ( $1=$ Extremely untolerable, $2=$ Untolerable, $3=$ Tolerable, $4=$ No crowding at all). These questions might be preceded by a visualization of the recent objective data on the vehicle configuration and the amount of standing (such as Figure 8). This will give the transport authority the percentages of public transport users who have experienced crowding (or overcrowding) recently, which then can be compared with the monitored objective crowding levels. If there is a significant gap between them, transport authorities should question whether the defined crowding measures are appropriate and develop measures that can better reflect travelers' experiences. ${ }^{15}$

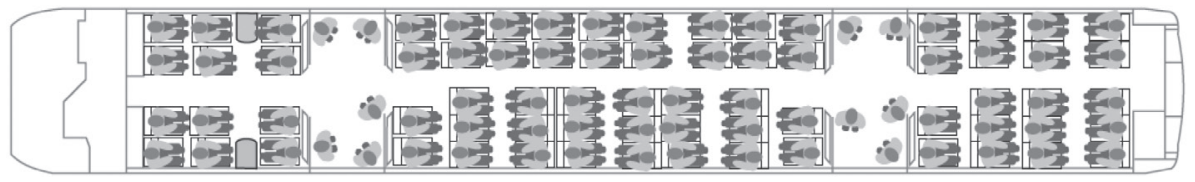

Source: Hensher et al. 2011

Figure 8. Example of crowding within a public transport mode

Another significant implication is associated with the management of crowding. One way to reduce crowding is to increase frequency or capacity so as to reduce passenger density (objective crowding), which is a common solution to overcrowding. Another strategy is directly linked to the subjective component of crowding. Given a level of objective crowding, traveler tolerance of crowding can be improved through better design or better services. Evans and Wener (2007) recommended 
that public transport designers should provide pairs of proximate seats, rather than three across seating; meanwhile, larger carriages or vehicles should be used to help compensate for the loss of seat space. Cox et al. (2006) suggested that design innovations should focus on passenger control over elements such as space, choice of seat, point of entry and exit, and others that enhance their perceptions of safety and security. In addition to the design of the carriage, Thompson et al. (2012) suggested a number of ways that may relieve crowding and improve the tolerance of crowding through providing better service, such as improving air quality and air circulation, establishing optimum frequency of trains, improving quality of communication, and improving cleanliness (especially of handholds and floors). Other strategies may also contribute to the reduction of perceived crowding, including improving reliability of services/reducing delays and discouraging or banning loud conversions and music in buses/train carriages.

\section{Linking Subjective and Objective Measures to Measurable Users Benefits for Inclusion in Benefit-Cost Analysis}

The discussion of objective and subjective measures of crowding in previous sections is informative in identifying ways to capture more than a measure of physical passenger density. There clearly are underlying user perceptions as to whether crowding is present or not (on an appropriate scale). This is all fine; however, it does not provide a quantitative metric of perceived crowding that can be converted, using a willingness-to-pay estimate, to a benefit improvement consequent on some change in service level.

The limited empirical evidence on the subjective dimensions that signal when crowding is present provides strong support for a measure of crowding that is not simply the defined standard but, rather, some metric that is in units that is correlated with the subjective influences and yet can be used in a modal choice model to proxy for the underlying derivatives of perceived levels of crowding. The literature on willingness to pay (see Li and Hensher 2011), together with a recent study by Hensher et al. (2011), suggest that visualization of the condition (capacity and crowding) of a carriage or bus together with a descriptor of the number seated and standing (as in Figure 8) can provide a rich definition of the situation often faced by travelers. ${ }^{16}$ How they perceive this in terms of a source of disutility (or dissatisfaction) should be obtained from the parameterization of an appropriately-specified crowding variable or function in a model choice model. Hensher et al. (2011) and Tirachini et al. (2012) find that two good proxy variables are density of standees per 
square meter and the proportion of seats occupied. These are specified by Tirachini et al. (2012) as linear and quadratic terms, and both are interacted with in-vehicle travel time in order to recognize that the marginal disutility is both a function of the level of crowding as defined by the two crowding dimensions and the amount of time in public transport.

The inclusion of these additional attributes in a mode choice model enables practitioners to assess the impact of improvements in capacity on the density of standees and the proportion of seats being used that matters to travelers (i.e., the subjective dimension). We have developed macros that enable feedback in a travel demand and supply model system, since it is not possible to predict the levels of these two variables without some equilibration. Once identified, associated willingness-to-pay estimates can be applied to convert the two sources of change in crowding to dollar net benefits.

\section{Conclusions and Recommendations}

This paper has reviewed the specifications of crowding measures defined by transport authorities in different countries (UK, U.S., and Australia). The bus industry, including BRT, tends to use a generic measure, namely the number of standing passengers per square meter, while for the rail industry, there are some variations in crowding measures (e.g., the number of standing passengers per square meter, load factor, rolling hour average loads). We suggest that for short journeys (e.g., commuting services), standing allowance should be treated as an additional component of capacity when defining crowding measures, while for long journeys (e.g., regional services), only the number of seat should be used as the capacity.

The broad transport crowding literature tends to focus on objective measures (e.g., passenger density). Only a few transport studies (see, e.g., Turner et al. 2004; Cox et al. 2006; Mohd Mahudin et al. 2012) have argued that the objective treatment of crowding (equivalent to density) cannot fully represent the experience of crowding, given that the perception of crowding is subjective. Given this, in addition to the objective measures (e.g., density), public transport operators/authorities should conduct perception surveys to obtain information on passenger subjective evaluations of crowding. Through surveys on perceived crowding, the transport authorities/operators can obtain the real experiences of passengers, which can be used to design more appealing measures to capture crowding and to calibrate the defined crowding thresholds to reflect the experienced crowding. Incorporating subjective measures of crowding can contribute to (1) a more accurate represen- 
tation of crowding, which would help operators manage and reduce crowding in time by implementing strategies such as increasing the frequency of service and using larger vehicles, and (2) a better understanding of crowding, which is beneficial to the design of more appealing public transport systems to attract more users.

This evidence can be used on an ongoing basis to ensure that proxy measures of perceived preferences for specific levels of crowding (as illustrated above by, e.g., Tirachini et al. 2012) that are incorporated in formal modal choice models that deliver the necessary outputs for benefit-cost analysis remain relevant. The challenge is to establish how much users are willing to pay to reduce crowding (to a specific level), as they perceive it, regardless of the standard, since this is a clear source of user benefit. Mapping this evidence, if available, to the standard, will enable a clearer picture to emerge of how the system is complying with the standard; however, this is not the basis of extracting the set of crowding-related benefits that exist regardless of the standard. If a move towards the standard ensures a gain in perceived user benefit, then it needs to be captured through a preference study. Simply imposing a desired standard does not capture the user benefit.

\section{Endnotes}

${ }^{1}$ In the U.S., load factor (the ratio of the number of passengers to the number of seats) is an alternative measure for bus crowding, which is specified not to exceed 1.2.

${ }^{2}$ Sourced from www.thejakartaglobe.com/international/bogotas-vaunted-transitsystem-model-for-transjakarta-in-distress/504689.

${ }^{3}$ The standard class capacity is based on the booked formation of the service and includes the number of standard class seats on the train and an allowance for standing for a service where there is a stop within 20 minutes, which is typically approximately $35 \%$ of the number of seats.

${ }^{4}$ The PiXC is a measure equivalent to the number of standing passengers per square meter.

${ }^{5}$ The TCQSM was initially published in 1999 as a comprehensive reference resource for U.S public transit practitioners and policy makers. The current TCQSM, 2nd Edition, was published in 2003 is widely used by transit service providers, metropolitan planning organizations, and state DOTs. In addition, the TCQSM is often used as a source of transit definitions and transit capacity and quality-of-service concepts. 
The 3rd edition, which addresses important changes that have occurred in public transit technologies, policies, practices, and procedures, is expected to release at the end of 2012.

${ }^{6}$ In accordance with the requirements of the Passenger Transport Act, Transport for NSW and RailCorp entered into a rail services contract that commenced on July1, 2010. This contract includes a range of Key Performance Indicators (KPI) to ensure service standards.

${ }^{7}$ The May 2011 survey was conducted from May 9-26, 2011.

${ }^{8}$ On May 8, 2011, 635 additional services were added across Melbourne's rail network (http://www.metrotrains.com.au/news/2011/feb/14/new-may-timetabledelivers-635-weekday-services). This improvement may be a reason that Melbourne's rail services were less crowded in May 2011 than previous years.

9 Some rail passengers' comments on crowding collected in 2011 include "We are like sardines in here. I am SO uncomfortable!"; "Completely packed train, every time, people having to skip and wait for next one"; "Max crush load, yet they still keep getting on the train"; "Not ok! I paid \$19, I should not have to sit on the floor"; "Too crowded in the aisles to access empty seats." The situation has not been improved in 2012. The worst overcrowding was observed on the Frankston line (away from Melbourne city center at 6 PM on January 23, 2012), with 200 people standing up in one carriage.

${ }^{10}$ Source from $\left.h t t p: / / a u . n e w s . y a h o o . c o m / v i d e o / n s w / w a t c h / 28278858 /\right)$.

${ }^{11}$ Melbourne's measure (see, e.g., Figure 2) can tell only the number (percentage) of services that exceeded the crowding benchmark. However, the number of passengers that exceeded the benchmark is crucial to the extent of crowding, which was ignored in Melbourne's crowding measure.

${ }^{12}$ Load factor and seat density were candidate variables to predict stress (the dependent variable, e.g., mood, during the commute to work, measured by fivepoint semantic differential scales [carefree-burdened; contented-frustrated]) in the regression model where seat density was statistically significant, while the overall load factor is not.

${ }^{13} \mathrm{~A}$ reviewer pointed out that some of the factors that have an impact on perceived crowding are completely outside the control of a transit agency (e.g., weather, body odor, and noisy school children). 
${ }^{14}$ The pictorial display of Figure 7 is a representation of objective measures of crowding (passenger density). However, when traveling in a bus or train with the same level of objective crowding, the perceived crowding levels may vary across public transport users, given that their previous experiences on crowding and tolerance of crowding may be different. In Mohd Mahudin et al. (2012), Figure 7 was presented to their subjects, who were required to rate the given density. As an example, with regard to the fourth level of crowding, some subjects may rate it as "extremely overcrowded" and some may rate it as "crowded."

${ }^{15}$ For example, the monitored crowding by the authority indicated that $25.8 \%$ and $23 \%$ of Melbourne train passengers were traveling on the crowded services during the morning and afternoon peak hours in 2011 (see Figures 2 and 3); however, an opinion survey conducted by Canstar Blue showed that $55 \%$ of surveyed Melburnian commuters reported that they experienced overcrowding on train services. This huge gap suggests that the crowding measure used in Melbourne (rolling hour average loads, where overcrowding is defined as more than 798 passengers per train during a given hour, on average) cannot correctly indicate experienced crowdedness. This example, in turn, illustrates the limitation of using only objective measures for representing crowding.

${ }^{16}$ Given that it allows for subjective perceptions of crowding, using visualization along with description is better than description only (e.g., "trips out of 10 for which you have to stand" in Hess et al. 2011) for the representation of the crowding attribute in the choice experiments.

\section{Acknowledgments}

Discussions with Alejandro Tirachini are greatly appreciated. We also thank a referee for some insightful comments and suggestions, which have contributed materially to improving this paper.

\section{References}

AQSIQ. (2004). Safety Specifications for Power Driving Vehicles Operating on Road. General Administration of Quality Supervision, Inspection and Quarantine of the People's Republic of China.

Audit Office of New South Wales. (2011). NSW Auditor-General's Report, Volume Eight. 2011 Rail Corporation New South Wales, NSW Government. 
Cox, T., and G. Gotts. (1987) The General Well-Being Questionnaire (GWBQ) Manual. Nottingham: Department of Psychology, University of Nottingham, Stress Research Unit.

Cox, T., J. Houdmont, and A. Griffiths, A. (2006). Rail passenger crowding, stress, health and safety in Britain. Transportation Research Part A-Policy and Practice 40(3): 244-258.

Day, A. T., and L. H. Day. (1973). Cross-national comparison of population density. Science 181(4104): 1016-1023.

Department of Infrastructure. (2008). East West Rail Link, analysis on rail capacity. Victorian Government, Australia.

Department of Transport. (2011). Metropolitan Train Peak Passenger Loads. Department of Transport, Victorian Government, Australia.

Diec, J., S. Coxon, and A. de Bono. (2010). Designing a public train station shelter to minimise anti-social behaviour and crime in Melbourne's metropolitan rail environment. Paper presented at the 33rd Australasian Transport Research Forum, Canberra, Australia.

Duarte, F. and C. Ultramari. (2012). Making public transport and housing match: Accomplishments and failures of Curitba's BRT. Journal of Urban Planning and Development 138(2): 183-194.

Evans, G. W. (1979). Design implications of spatial research. In Aiello, J. R., and A. Baum (eds.), Residential Crowding and Design. Plenum, New York.

Evans, G. W., and R. E. Wener. (2007). Crowding and personal space invasion on the train: Please don't make me sit in the middle. Journal of Environmental Psychology 27(1): 90-94.

Evans, G. W., S. J. Lepore, and K. Mata-Allen. (2000). Cross-cultural differences in tolerance for crowding: Fact or fiction? Journal of Personality and Social Psychology 79(2): 204-210.

Gotts, G., and T. Cox. (1988). Stress And Arousal Checklist: A Manual for Its Administration, Scoring and Interpretation. Swinburne University Press, Melbourne.

Hensher, D. A., P. Stopher, and P. Bullock. (2003). Service quality-Developing a service quality index in the provision of commercial bus contracts. Transportation Research Part A 37(6): 499-517. 
Hensher, D. A., J. M. Rose, and A. T. Collins. (2011). Identifying commuter preferences for existing modes and a proposed metro. Public Transport-Planning and Operations 3(2): 109-147.

Hess, S., A. Stathopoulos, D. Campbell, V. O'Neill, and S. Caussade. (2011). It's not that I don't care, I just don't care very much: Confounding between attribute non-attendance and taste heterogeneity. Paper presented at the European Transport Conference, Glasgow, October 2011.

Hirsch, L., and K. Thompson. (2011). I can sit but I'd rather stand: Commuters' experience of crowdedness and fellow passenger behaviour in carriages on Australian metropolitan trains. Paper presented at the 34th Australasian Transport Research Forum, Adelaide, South Australia, Australia.

Hirsch, L., K. Thompson, and S. Mueller. (2011). A socio-economic study of carriage and platform crowding in the Australian railway industry: Brochure of findings. CRC for Rail Innovation, Brisbane, Australia.

Ibrahim, M. F. (2003). Car ownership and attitudes towards transport modes of shopping purposes in Singapore. Transportation 30(4): 435-457.

ITDP. (2012). The BRT Standard Version 1.0. Institute for Transportation and Development Policy, New York.

Jacobs Consultancy. (2010). South Fulham Riverside Planning Framework. Transport Study Report, Jacobs Consultancy.

Joireman, J. A., P. A. Lange, M. Kuhlman, M. V. Vugt, and G. P. Shelley. (1998). An interdependence analysis of commuting decisions. European Journal of Social Psychology 27(4): 441-463.

Li, Z., and D. A. Hensher. (2011). Crowding and public transport: A review of willingness to pay evidence and its relevance in project appraisal. Transport Policy 18(6): 880-887.

London Assembly Transport Committee. (2009). The big squeeze: Rail overcrowding in London. Greater London Authority, London, England.

Mohd Mahudin, N. D., T. Cox, and A. Griffiths, A. (Forthcoming). The effects of rail passenger crowding on health and stress: A systematic review. Accepted pending minor revisions. 
Mohd Mahudin, N. D., T. Cox, and A. Griffiths, A. (2012). Measuring rail passenger crowding: Scale development and psychometric properties. Transportation Research Part F 15(1): 38-51.

Nair, P., and D. Kumar. (2005). Mumbai urban transport project: Development and challenges. The ICFAI Journal of Infrastructure, March: 34-42.

Nunnally, C., and I. Bernstein, I. (1994). Psychometric Theory (3rd ed.). McGraw-Hill, New York.

Office of Rail Regulation. (2011). Peak crowding and passenger demand. UK Government.

Queensland Rail. (2011). More customers, less crowding as new timetable delivers. Ministerial Media Statement.

Sundstrom, E. (1978) Crowding as a sequential process: Review of research on the effects of population density on humans. In Baum, A., and Y. M. Epstein (eds.), Human Response to Crowding. Hillsdale Erlbaum, New York.

Sundstrom, E. B., P. Busby, and C. Asmus. (1975). An experimental study of crowding: Effects of room size, intrusion, and goal blocking on nonverbal behavior, self-disclosure, and self-reported stress. Journal of Personality and Social Psychology 32(4): 645-654.

Thompson, K., L. Hirsch, S. Muller, and S. Rainbird. (2012.) A socio-economic study of carriage and platform crowding in the Australian railway industry: Final report. CRC for Rail Innovation, Brisbane, Australia.

Tirachini, A., D. A. Hensher, and J. M. Rose. (2012). Multimodal pricing and optimal design of public transport services: The interplay between traffic congestion and bus crowding. Twelfth International Conference on Advanced Systems for Public Transport, Santiago, Chile, July (www.caspt.org).

Transport Committee. (2003). Overcrowding on Public Transport. The Transport Committee, UK.

Transportation Research Board (TRB). (2003). Transit Capacity and Quality of Service Manual, 2nd Edition, Transportation Research Board, USA.

TRB. (2006). TCRP Report 113: Using Archived AVL-APC Data to Improve Transit Performance and Management. Transportation Research Board. 
Turner, S., E. Corbett, R. O'Hara, and J. White. (2004) Health and safety effects of rail crowding: Hazard identification. HSL Report RAS/04/12.

UITP. (2009). Bus systems an efficient mode of transport. International Association of Public Transport.

UK Rail Safety and Standards Board. (2004). Crowd management at stations: A good practice guide. Rail Safety and Standards Board, London.

Van Der Reis, A. P. (1983). Black commuting in Pretoria: Attitudes towards crowding. National Institute for Transport \& Road Research, Special Report BCP 9, South Africa.

Worchel, S., and C. Teddlie. (1976). The experience of crowding: A two-factor theory. Journal of Personality and Social Psychology 34(1): 30-40.

\section{Appendix A: Measuring Subjective Evaluations of Crowding or Perceived Crowdedness (Mohd Mahudin et al. 2012)}

1. Below are 7 categories of items that ask you about "How crowded is the train that vou are on today?" (A, B, C, D, E, F, \& G). Please circle or tick one answer in each of these categories.

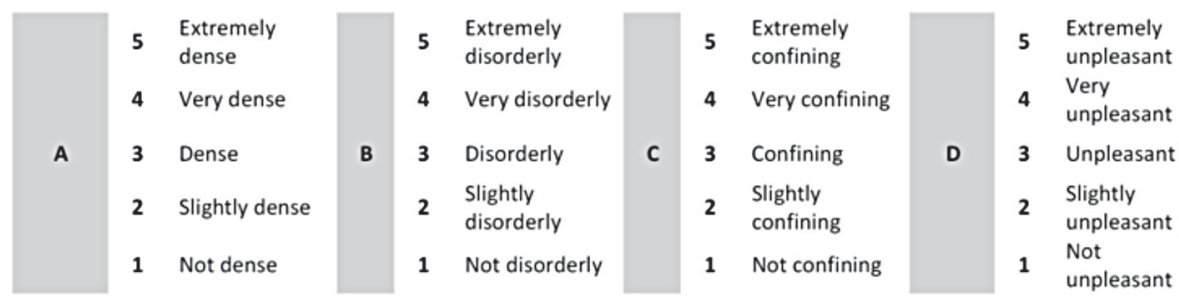

\begin{tabular}{|c|c|c|c|c|c|c|c|c|}
\hline & 5 & Extremely chaotic & & 5 & $\begin{array}{l}\text { Extremely } \\
\text { disturbing }\end{array}$ & & 5 & $\begin{array}{l}\text { Extremely } \\
\text { cluttered }\end{array}$ \\
\hline & 4 & Very chaotic & & 4 & Very disturbing & & 4 & Very cluttered \\
\hline $\mathbf{E}$ & 3 & Chaotic & $\mathbf{F}$ & 3 & Disturbing & G & 3 & Cluttered \\
\hline & 2 & Slightly chaotic & & 2 & Slightly disturbing & & 2 & Slightly cluttered \\
\hline & 1 & Not chaotic & & 1 & Not disturbing & & 1 & Not cluttered \\
\hline
\end{tabular}


2. Below are 9 categories of items that ask you about "How you feel inside the train that you commute on today?" (A, B, C, D, E, F, G, H, \& I). Please circle or tick one answer in each of these categories.

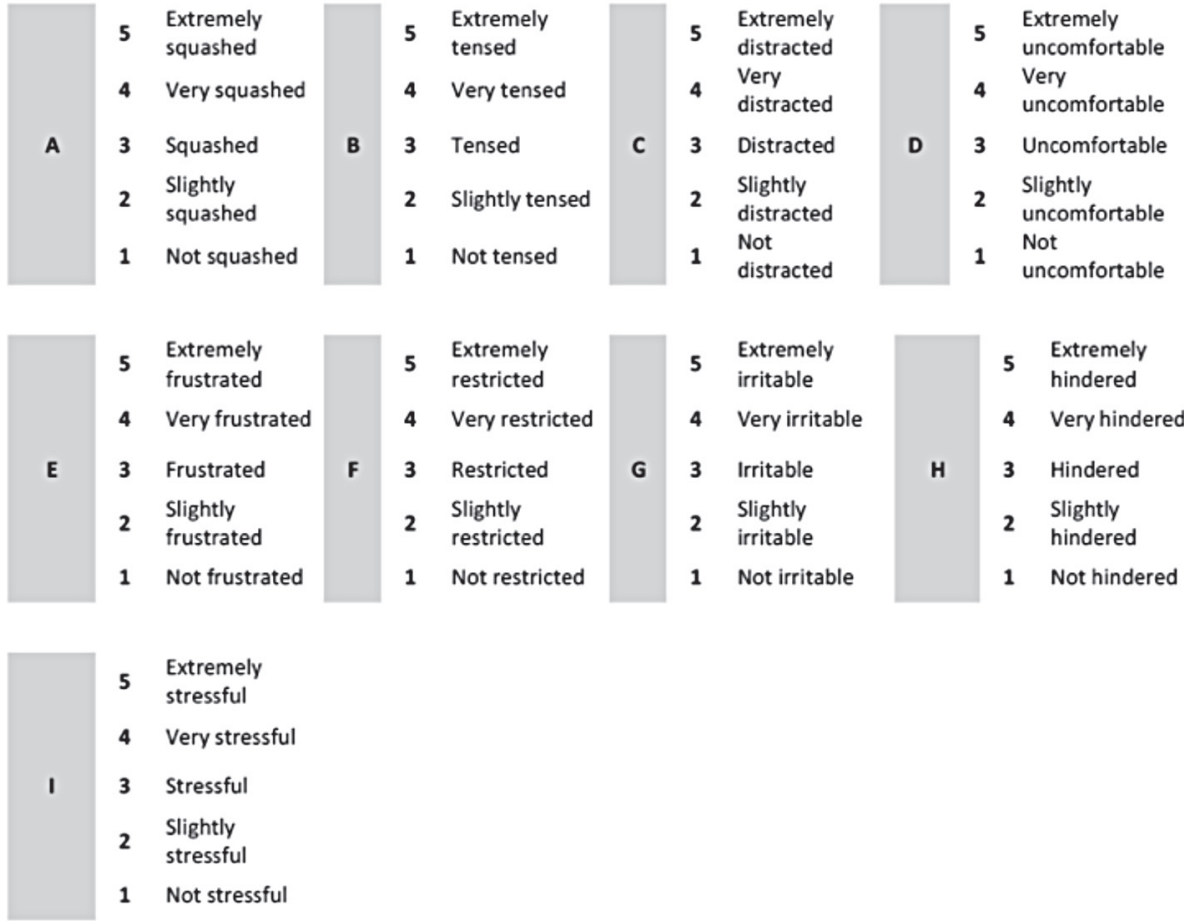

3. Below are 4 categories of items that ask you about "The physical environment inside the train that you commute on today" (A, B, C, \& D). Please circle or tick one answer in each of these categories.

\begin{tabular}{|c|c|c|c|c|c|c|c|c|c|c|c|}
\hline & 5 & Extremely hot & & 5 & $\begin{array}{l}\text { Extremely } \\
\text { stuffy }\end{array}$ & & 5 & $\begin{array}{l}\text { Extremely } \\
\text { smelly }\end{array}$ & & 5 & Extremely noisy \\
\hline & 4 & Very hot & & 4 & Very stuffy & & 4 & Very smelly & & 4 & Very noisy \\
\hline A & 3 & Hot & B & 3 & Stuffy & C & 3 & Smelly & D & 3 & Noisy \\
\hline & 2 & Slightly hot & & 2 & Slightly stuffy & & 2 & Slightly smelly & & 2 & Slightly noisy \\
\hline & 1 & Not hot & & 1 & Not stuffy & & 1 & Not smelly & & 1 & Not noisy \\
\hline
\end{tabular}




\section{About the Authors}

ZHeNG LI (Zheng.Li@sydney.edu.au) is Senior Research Fellow in Transportation at the Institute of Transport and Logistics Studies (ITLS) in The University of Sydney Business School. His main research interests include willingness to pay valuation (e.g., travel time variability), advanced non-linear travel choice models, and transport policy. He is currently working with Professor David Hensher on a number of research projects including two ARC-DP grants, BRT, TRESIS Model Updating, Transport Opinion Survey (TOPS), and Travel Time Variability/Reliability Measure and Valuation. Before his role as Senior Research Fellow, he worked as a research analyst (part-time) at ITLS, while undertaking his full-time research degrees (MPhil awarded in 2008; PhD submitted in 2012). He has published more than 20 journal articles, the majority of which are published in the top transportation and logistics journals (e.g., Transportation Research Parts A, B, D and E, Transportation Science, Transportation), and he has presented papers at a number of international conferences. In 2010, he was awarded the Institute of Transport and Logistics Studies Prize for research excellence in transport or logistics.

David Hensher (David.Hensher@sydney.edu.au) is Professor of Management and Founding Director of the Institute of Transport and Logistics Studies (ITLS) at The University of Sydney. He is the recipient of the 2009 IATBR Lifetime Achievement Award in recognition for his longstanding and exceptional contribution to IATBR as well as to the wider travel behavior community and the recipient of the 2006 Engineers Australia Transport Medal for lifelong contribution to transportation. He is a member of Singapore Land Transport Authority International Advisory Panel (chaired by the Minister of Transport) and Past President of the International Association of Travel Behaviour Research. He has published extensively (500+ papers) in the leading international transport journals and key journals in economics and in 14 books. 